\title{
FUENTES DEMOGRÁFICAS PARA EL ESTUDIO DE LA MIGRACIÓN EN ESPAÑA
}

\author{
Joaquín Susino*
}

\begin{abstract}
En este trabajo se presentan las fuentes disponibles en España para analizar la evolución de las migraciones, centrándonos en la cuantificación de los efectivos de migrantes y los flujos de migración. Se consideran tanto las migraciones interiores como las internacionales, dado que muchas fuentes permiten estudiar ambas. Se diferencian las fuentes específicamente estadísticas frente a las que se apoyan en registros administrativos, así como las que estudian el universo completo frente a las basadas en encuestas, insistiendo en la necesidad de diferenciar rigurosamente entre efectivos y flujos.
\end{abstract}

Palabras clave: Fuentes Estadísticas; Migraciones Interiores; Migrantes; Extranjeros.

\section{Introducción}

Este artículo trata sobre la cuantificación de las migraciones, tanto interiores como internacionales, en España. Presenta las fuentes disponibles para su estudio y analiza la evolución reciente de tales migraciones a partir de dichas fuentes. Pero esta tarea requiere algunas precisiones conceptuales previas.

En primer lugar, el concepto de migración tiene una doble dimensión, espacial y temporal, que plantea especiales dificultades para su medición, que en otros fenómenos demográficos no se dan, como la fecundidad o la mortalidad. Se entiende por migración el cambio de residencia habitual de un individuo que implica atravesar algún tipo de división geográfica. ${ }^{1}$ Definición en la que aparece esa doble dimensión temporal y espacial.

\footnotetext{
* Doctor en Sociología, profesor e investigador del Departamento de Sociología de la Universidad de Granada. E-mail: jsusino@ugr.es. Granada/España.

1 UIAA. Diccionario demográfico multilingüe.
} 
Por lo que se refiere a la dimensión espacial, normalmente las divisiones geográficas consideradas son administrativas y varían mucho de unos países a otros. En España la más pequeña división a estos efectos es el municipio; al igual que en la mayoría de los países latinoamericanos, aunque en algunos reciba denominaciones como cantón, comuna o distrito. Aunque otras definiciones de migración son posibles², la medición de las migraciones se facilita mucho si nos atenemos a los cambios de residencia entre municipios, que es la opción más asentada a nivel internacional. El problema es que esas unidades administrativas son muy diferentes entre los países, por tamaño y estructura interna de los asentamientos de población, lo que incide en el volumen de movimientos que se definen como migraciones. A este respecto las grandes perjudicadas son las migraciones internas, no así las migraciones internacionales que no tienen problemas de definición en cuanto a su dimensión espacial: las fronteras de los Estados. ${ }^{3}$

Por lo que se refiere a la dimensión temporal, ¿qué entendemos por residencia habitual? ¿Qué duración mínima de estancia en otro lugar es necesaria para considerarla como tal? Tras estas preguntas no hay solo una dimensión temporal, sino motivacional. Es difícil precisar el momento exacto en el que se produce la migración. ¿Cuando alguien hace mudanza o cuando decide establecerse aunque ya lleve algún tiempo en el lugar de forma presuntamente temporal? La mayoría de sistemas estadísticos dejan a la interpretación del ciudadano interrogado qué entiende y cuándo cree que cambió de lugar de residencia habitual. La dimensión temporal de las migraciones afecta a las migraciones interiores e internacionales.

En segundo lugar, hay que diferenciar entre migración y migrante, entre flujos y efectivos. Los migrantes son los que en un momento determinado están en una población porque han migrado en relación a un momento o periodo determinado anterior (son un efectivo o un stock y se miden en un instante del tiempo); las migraciones son todos y cada uno de los desplazamientos migratorios realizados por un individuo durante un periodo de tiempo (son una variable flujo y se miden a lo largo de un periodo). Lógicamente las migraciones superan al número de migrantes existentes, porque a cada migrante corresponde al menos una migración, pero puede haber hecho más de una en el periodo que estemos considerando. En la investigación sobre las migraciones se puede preguntar a los sujetos, bien por cada una de las migraciones realizadas, bien

\footnotetext{
2 Por ejemplo, es bien conocida la de Courgeau (Méthodes de mesure de la mobilité spatiale), que las define como cambios en el espacio de vida de los sujetos, pero pueden plantearse otras que se atengan a la estructura territorial del sistema de asentamientos, en lugar de a la división administrativa del territorio.

3 POULAIN, Michel. "La mesure de la migration internationale".
} 
por su condición de migrante en relación con un determinado momento. Unas estadísticas pueden medir migrantes y otras migraciones, y algunas ambas cosas a la vez. Es necesario insistir en la necesidad de diferenciar entre efectivo y flujos, migrantes y migraciones, porque su confusión da lugar a muchos malentendidos y a graves errores de interpretación. ${ }^{4}$

En tercer lugar, como proceso social que implica tiempo y espacio, su estudio exige una información adicional que nos obliga a preocuparnos por las características demográficas típicas de edad y sexo de los migrantes, así como por otras características sociales, como la relación con la actividad económica, la situación familiar, la condición socioeconómica u ocupación,... Además, su dimensión geográfica, nos exige estudiar los flujos migratorios entre los lugares de origen de la emigración y los lugares de destino de la inmigración. Las fuentes estadísticas sobre migraciones deben permitir su estudio y no solo la cuantificación de migraciones o migrantes. No obstante en este trabajo nos centramos en su medición y evolución, con una breve referencia a esas otras dimensiones del fenómeno.

\section{Clasificación de las fuentes estadísticas para el estudio de las migraciones}

Podemos considerar dos grandes tipos de fuentes estadísticas para el estudio demográfico de las migraciones: las fuentes elaboradas con fines específicamente estadísticos; las fuentes administrativas de las que se extraen estadísticas. En general, las primeras suelen ser más fiables que las segundas, porque están elaboradas con el objetivo explícito de medir el fenómeno en cuestión, en nuestro caso la migración; mientras que las segundas se apoyan en procesos administrativos que se aprovechan para extraer estadísticas, ya sea para el control de la propia gestión administrativa o con fines de conocimiento más amplios. Pero hay que tener en cuenta que los procesos administrativos responden a su propia lógica, la de la gestión a la que sirven y la de los propios ciudadanos que se sirven de ella, por lo que las estadísticas resultantes están condicionadas por esta lógica de uso y gestión.

Otra posible distinción entre fuentes se refiere a las que son universales frente a las muestrales. Las primeras registran o cuentan todos los movimientos o todos los migrantes, ya sea mediante estadísticas expresamente diseñadas para ello (censos) o registros administrativos (EVR). Las segundas investigan mediante encuesta (EPA y ESD) a una muestra, a partir de la cual se infiere el volumen total de migraciones y migrantes en el conjunto de la población. Los

${ }^{4}$ COHEN, Arón. "Reflexiones a propósito de una lectura estadística de la inmigración. La inmigración entre imágenes y cifras". 
registros administrativos aspiran a la universalidad, pero siempre en función de de los propios procesos administrativos en que se sustentan. Así, por ejemplo, un registro de extranjeros con permiso de residencia no comprenderá, por definición a todos los residentes extranjeros, solo a los que tiene residencia legal.

\section{CUADRO 1 \\ Clasificación de las fuentes estadísticas españolas sobre migraciones}

\begin{tabular}{|c|c|c|c|}
\hline \multirow[t]{2}{*}{$\begin{array}{l}\text { Con fines } \\
\text { específi- } \\
\text { camente } \\
\text { estadísticos }\end{array}$} & $\begin{array}{l}\text { Censos } \\
\text { universales }\end{array}$ & $\begin{array}{l}\text { - Censos de Población y vivienda de } \\
\text { 1970, 1981, } 1991 \text { y } 2001 \\
\text { - Padrones de Habitantes de } 1975 \text { y } \\
1986\end{array}$ & $\begin{array}{l}\text { - Interiores e } \\
\text { internacionales } \\
\text { - Ambas }\end{array}$ \\
\hline & $\begin{array}{l}\text { Estadísticas } \\
\text { basadas en } \\
\text { muestras }\end{array}$ & $\begin{array}{l}\text { - Encuesta de Migraciones desde } 1980 \\
\text { - Encuesta Sociodemográfica de } 1991 \\
\text { - Encuesta Nacional de Inmigrantes de } \\
2007 \\
\text { - Censo de Población de } 2011\end{array}$ & $\begin{array}{l}\text { - Ambas } \\
\text { - Ambas } \\
\text { - Internacionales } \\
\text { - Ambas }\end{array}$ \\
\hline \multirow[t]{3}{*}{$\begin{array}{l}\text { Registros } \\
\text { adminis- } \\
\text { trativos } \\
\text { explotados } \\
\text { estadística- } \\
\text { mente }\end{array}$} & $\begin{array}{l}\text { De pobla- } \\
\text { ción }\end{array}$ & $\begin{array}{l}\text { - Padrón municipal de Habitantes } \\
\text { - Estadísticas de Variaciones Residen- } \\
\text { ciales } \\
\text { - Padrón de Españoles Residentes en el } \\
\text { Extranjero }\end{array}$ & $\begin{array}{l}\text { - Ambas } \\
\text { - Ambas } \\
\text { - Internacionales }\end{array}$ \\
\hline & De policía & $\begin{array}{l}\text { - Autorizaciones de residencia } \\
\text { - Control de fronteras y Visados } \\
\text { - Solicitudes de asilo }\end{array}$ & $\begin{array}{l}\text { - Internacionales } \\
\text { - Internacionales } \\
\text { - Internacionales } \\
\end{array}$ \\
\hline & Laborales & $\begin{array}{l}\text { - Autorizaciones de trabajo } \\
\text { - Trabajadores afiliados a la Seguridad } \\
\text { Social }\end{array}$ & $\begin{array}{l}\text { - Internacionales } \\
\text { - Ambas }\end{array}$ \\
\hline
\end{tabular}

Fuente: elaboración propia.

Por último, hay fuentes específicas sobre migraciones internacionales, pero muchas otras permiten estudiar tanto las internacionales como las interiores, por lo que en este trabajo tal criterio será secundario. A pesar de que en la literatura académica se tiende a estudiar ambos tipos de migraciones separadamente, por lo que algunos autores se centran en las fuentes para las migraciones interiores ${ }^{5}$, y otros en las internacionales. ${ }^{6}$ En la presentación que sigue vamos a combinar estos criterios de clasificación, dando prioridad a los dos primeros.

\section{Los censos de población}

Los censos son la fuente más típicamente demográfica y la primera que aparece en el sistema estadístico español. Los censos modernos se

5 GARCÍA COLL, Arlinda. "Migraciones interiores y transformaciones territoriales".

6 LÓPEZ de Lera, Diego; DOMÍNGUEZ, Iciar. Inmigración Extranjera en Andalucía 1991-2001; IZQUIERDO, Antonio (dir.). Demografía de los extranjeros. Incidencia en el crecimiento de la población. 
caracterizan por ser una operación institucional, elaborados con fines estadísticos y de carácter universal (se investiga a toda la población, no a una muestra). ${ }^{7}$ Sin embargo, el censo de 2011, del que todavía no se poseen resultados, difiere de todos los anteriores porque está basado en registros administrativos y completado con una encuesta a una muestra muy amplia, de aproximadamente un $12 \%$ de la población. De todas formas aunque los censos anteriores eran universales, solo en los de 1991 y 2001 se explotó la totalidad de los cuestionarios, mientras que en los anteriores la mayor parte de las preguntas se explotaban para una muestra de los cuestionarios recogidos. Con todo, los censos no siempre han incluido preguntas específicas sobre migraciones y pueden ser consideradas fuentes distintas, dependiendo del tipo de pregunta utilizada. Podemos considerar tres tipos de preguntas:

- La única pregunta que está presente en los censos más antiguos, desde el siglo XIX, no es específica sobre migraciones, se refiere al lugar de nacimiento. Su uso para el estudio de las migraciones se deriva de la comparación entre el lugar de residencia y el lugar de nacimiento. No deja de ser, sin embargo, una fuente relevante, porque es la única existente para determinados periodos. ${ }^{8}$

\section{CUADRO 2}

Población según relación entre lugar de residencia y lugar de nacimiento

\begin{tabular}{c|c|r|r|r|r|r}
\cline { 2 - 7 } & $\mathbf{1 9 5 0}(\mathbf{1})$ & $\mathbf{1 9 6 0}(\mathbf{2})$ & $\mathbf{1 9 7 0}(\mathbf{2})$ & $\mathbf{1 9 8 1}(\mathbf{2})$ & $\mathbf{1 9 9 1}(\mathbf{2})$ & $\mathbf{2 0 0 1}(\mathbf{2})$ \\
\hline Total & 27.976 .755 & 30.528 .539 & 34.040 .643 & 37.683 .363 & 38.872 .268 & 40.847 .371 \\
\hline Mismo municipio & 19.931 .739 & 20.037 .895 & 20.231 .614 & 20.270 .635 & 20.226 .774 & 19.809 .314 \\
\hline $\begin{array}{c}\text { Distinto municipio de la } \\
\text { misma provincia }\end{array}$ & 3.677 .206 & 4.604 .908 & 5.741 .257 & 7.904 .224 & 9.098 .446 & 10.216 .696 \\
\hline Distinta provincia & 4.205 .564 & 5.473 .965 & 7.702 .396 & 8.863 .959 & 8.701 .071 & 8.649 .160 \\
\hline Nacido en el extranjero & 160.506 & 213.968 & 365.376 & 631.546 & 845.977 & 2.172 .201 \\
\hline No consta & 1.740 & 197.803 & & 12.998 & & \\
\hline
\end{tabular}

Fuente: elaboración propia a partir de los censos de población, INE.

(1) Población de hecho; (2) Población de derecho o residente habitual.

Los cambios en la población según su lugar de nacimiento son un reflejo de las migraciones, aunque no sean datos directamente de migraciones. En la figura 1, al comparar las variaciones entre censos sucesivos, se puede ver el enorme volumen que debieron tener en los años sesenta las migraciones interiores de más larga distancia, las interprovinciales, a juzgar por el gran

\footnotetext{
A los censos se pueden asimilar las renovaciones del Padrón de Habitantes de 1975 y 1986, por ser operaciones estadísticas de la misma naturaleza que los censos y con cuestionarios similares.

8 SILVESTRE RODRÍGUEZ, Javier. "Viajes de corta distancia: una visión espacial de las migraciones interiores en España 1877-1930".
} 
aumento de las personas que vivían en una provincia distinta de la que les vio nacer. También se puede ver que si en los años 80 y 90 esta variación resultaba negativa posiblemente se debiese al predominio del retorno de los antiguos emigrantes, si no a sus municipios, sí a sus provincias de origen. El aumento en los 70 de los nacidos en el extranjero se debe tanto a la creciente apertura de España al exterior como al retorno de los hijos de los emigrantes; mientras que en los 90 se debe a la conversión del país en tierra de inmigración.

\section{FIGURA 1 \\ Variación intercensal de la población según relación entre lugar de residencia y lugar de nacimiento}

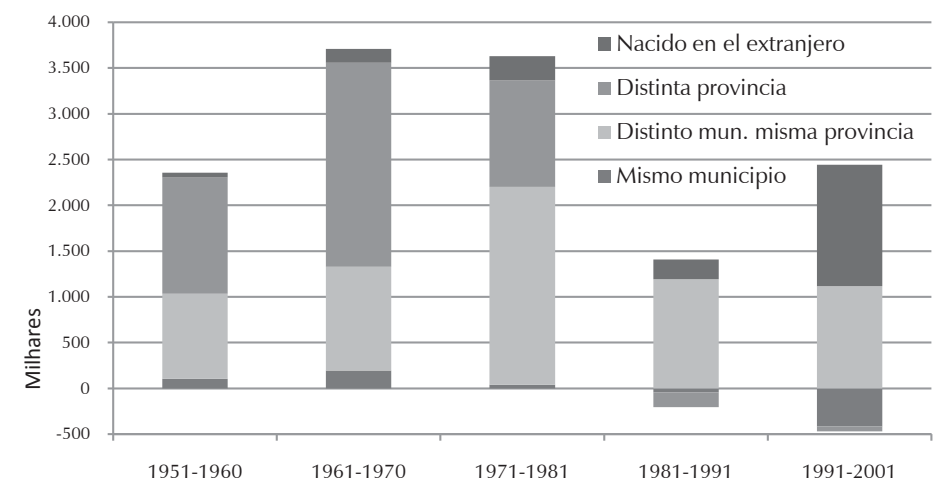

Fuente: elaboración propia a partir de los datos del cuadro 2.

- La primera pregunta específica sobre migraciones, incluida por primera vez en el censo de 1970, es la referida al lugar de residencia en una fecha fija anterior. Desde entonces, ha estado presente en todos los censos, siempre referida a la fecha de realización del censo anterior. ${ }^{9}$ Este tipo de cuestiones se limita a la población que había nacido en la fecha de referencia, es decir a la de diez años y más en el caso de que el periodo intercensal sea de diez años exactos. No es la fuente más utilizada, ${ }^{10}$ sin embargo, a nuestro juicio, es la más fiable para estudiar la evolución de las migraciones en el largo plazo. ${ }^{11}$ En todos los censos se ha formulado de forma muy parecida, se

\footnotetext{
9 Aunque el censo de 1991 incorpora una batería de tres preguntas referidas al lugar de residencia en el censo anterior, en la fecha de la renovación anterior del padrón (unos cinco años) y un año antes. También está presente en el censo de 2011, del que todavía no hay datos.

${ }^{10}$ GARCÍA COLL, Arlinda; STILLWELL, John. "Internal migration and regional population dynamics in Europe: Spain case study"; FERIA, José María et alii. Migraciones y movilidad residencial en Andalucía. 1991-2001.

${ }^{11}$ SUSINO, Joaquín. "La evolución de las migraciones interiores en España: una evaluación de las fuentes demográficas disponibles".
} 
refiere siempre a un periodo similar ${ }^{12}$ y ese periodo está cerrado. Se refiere a un efectivo de migrantes: los que viven en un municipio diferente en el año censal en relación al censo anterior. Entre las desventajas está que cada migrante aparece una sola vez, aunque haya realizado varias migraciones durante el periodo, no aparece como migrante quien haya vuelto al lugar de residencia de partida a lo largo del periodo, y no recoge los migrantes de menos de diez años.

\section{CUADRO 3}

Migrantes en los cuatro últimos periodos intercensales, según la relación entre la residencia actual y la del censo anterior

\begin{tabular}{l|r|r|r|r}
\cline { 2 - 5 } & $\mathbf{1 9 6 1 - 1 9 7 0 ( \mathbf { 1 } )}$ & $\mathbf{1 9 7 1 - 1 9 8 1} \mathbf{( 1 )}$ & $\mathbf{1 9 8 1 - 1 9 9 1}$ & $\mathbf{1 9 9 1 - 2 0 0 1}$ \\
\hline Intraprovinciales & 1.703 .083 & 1.912 .468 & 2.086 .030 & 2.483 .477 \\
\hline Interprovinciales & 2.543 .346 & 1.894 .212 & 1.617 .093 & 1.316 .932 \\
\hline Del extranjero (1) & 226.686 & 401.839 & 409.752 & 978.412 \\
\hline Total inmigrantes & 4.473 .115 & 4.208 .548 & 4.112 .875 & 4.778 .821 \\
\hline
\end{tabular}

Fuente: elaboración propia a partir de los censos de población, INE, varios años.

(1) En estos periodos otros territorios que entonces eran territorio espanõl se han excluido del ámbito interno e incorporado al extranjero, con objeto de que el espacio geográfico de referencia no varíe.

A lo largo de las cuatro décadas analizadas se ve el enorme volumen que en los años 60 alcanzaron las migraciones interiores de más larga distancia, las interprovinciales, y su descenso posterior; sobre todo si tenemos en cuenta que la población en 1970 era de casi 7 millones menos de personas que en 2001. Mientras tanto aumentaron las migraciones de corta distancia, las intraprovinciales, pero no en cantidad suficiente para compensar el descenso de la interprovinciales. Este aumento se debe en gran medida al incremento de la movilidad residencial metropolitana. ${ }^{13}$

Por lo que se refiere a la inmigración proveniente del extranjero hay que señalar que hasta los 80 buena parte era de emigrantes españoles que retornaban al país, consecuencia de que hasta mediados los 70 España era tierra de emigración. Mientras que en los 90 se produce un enorme aumento de la inmigración de extranjeros.

- La segunda pregunta específica sobre migraciones que se ha utilizado en los censos es la referida al lugar de residencia anterior al actual, es decir,

\footnotetext{
12 Hasta el de 1970 los censos tenían como fecha de referencia el 31 de diciembre de los años acabados en cero, los censos de 1981 y 1991 el 1 de marzo y el de 2001 y de 2011 el 1 de noviembre; por tanto los periodos son de 10 años, 10 años y 2 meses, 10 años y 10 años y 8 meses y de nuevo 10 años.

${ }^{13}$ FERIA, José María; SUSINO, Joaquín. "La dimensión regional y los nuevos referentes de las migraciones interiores en España".
} 
a la última migración, ya sea sin límite temporal o en el período que va de un censo a otro. Con diferentes redacciones esta pregunta se realizó en los censos de 1991 y 2001 y también se ha incluido en el de 2011. También estuvo presente en las renovaciones de los padrones de 1975 y 1986, que, estadísticamente, pueden considerarse equivalentes a los censos por tratarse de recuentos universales de población que emplean la misma técnica de recogida de datos, aunque tengan una calidad desigual. Tampoco es esta pregunta la más utilizada en las investigaciones recientes. ${ }^{14}$ La desventaja que tiene con respecto a la anterior es que no tiene un periodo de referencia claro, pues la última migración es más o menos cercana en función de la experiencia migratoria de cada persona. Podemos decir que, en cierta manera, deforma el tiempo. Más adelante, en el cuadro 3 se comparan sus resultados con los de otras preguntas y fuentes.

\section{Registros de población: el padrón de habitantes}

En algunos países existe un registro de la población, cuto objeto principal es el conocimiento administrativo del lugar de residencia de los habitantes del país. En España ese registro se llama Padrón Municipal de Habitantes, porque su gestión recae sobre los ayuntamientos de cada uno de los municipios españoles, con el apoyo de otras administraciones y la supervisión del INE. Existe desde hace décadas, pero hasta 1996 el padrón se renovaba completamente cada cinco años, actualizándose en los intervalos anuales siguiendo un procedimiento administrativo que no garantizaba que a cada alta en el padrón como consecuencia de una migración interior le correspondiese una baja en otro municipio. Solo desde 1996, el padrón se ha convertido en un registro continuo que garantiza la inexistencia de empadronamientos duplicados.

El padrón de habitantes tiene, estadísticamente, una doble función en la medición de la migración. Por una parte, permite una aproximación al efectivo de migrantes a principios de cada año recurriendo a las preguntas sobre lugar de nacimiento y sobre nacionalidad. Por otra parte, permite conocer los flujos migratorios, tanto interiores como internacionales, explotando estadísticamente las altas y bajas padronales.

- Por lo que se refiere al efectivo de inmigrantes, la explotación en función del lugar de nacimiento es muy parecida a la que ya hemos visto en los censos, aunque más adelante la volveremos a retomar para compararla con la población de extranjeros y con otros registros. Al igual que los censos, pero de forma continua, año a año, esta fuente permite estudiar la evolución del número de extranjeros empadronados. Este registro en España tiene

${ }^{14}$ CRUZ VILLALÓN, Josefina et alii. Los movimientos migratorios con origen y destino en Andalucía. 1981-1991. 
una característica diferencial y es que en él puede darse de alta cualquier extranjero residente en el país, con independencia de que tenga o no permiso de residencia. En otros países los extranjeros sin permiso de residencia no pueden incluirse en el registro de población.

Sin embargo, no siempre los extranjeros sin residencia legal han podido empadronarse, como reconoce explícitamente la Ley sobre derechos y libertades de los extranjeros en España del año 2000, conocida como ley de Extranjería. A partir de entonces el número de extranjeros empadronados se eleva por encima del número de permisos de residencia en vigor. Poco después se constata que, puesto que no se exige presentarse físicamente en los ayuntamientos para empadronarse, algunos extranjeros empadronan a familiares y amigos no residentes (que nunca han pisado el país) con objeto de poder documentar una supuesta presencia y arraigo en España en futuras operaciones de regularización de residencia.

Por otra parte, los extranjeros raramente se dan de baja cuando dejan de residir en España, con lo que el número de extranjeros empadronados tendería a crecer indefinidamente. Para evitarlo se introdujo una modificación legal en 2003 por la que se obliga a todo extranjero extracomunitario sin permiso de residencia permanente a renovar su empadronamiento cada dos años, o de lo contrario se produce la caducidad de su inscripción en el padrón. Las primeras bajas por caducidad empezaron a producirse en 2006. Es así que, tanto el funcionamiento administrativo del padrón, condicionado por los cambios normativos, como el uso que los administrados hacen de él, se convierten en fuentes de errores y discontinuidades en las series estadísticas.

- Por lo que se refiere a la explotación de las altas y bajas en el padrón, la fuente específica se denomina Estadísticas de Variaciones Residenciales (EVR). Existen desde principios de los años sesenta, aunque entonces aun no recibían ese nombre, pero, a lo largo de este tiempo, han experimentado cambios muy profundos ligados a la gestión del padrón, habiendo mejorado mucho a partir de 1996, cuando se implanta el padrón continuo. Anteriormente, en relación con la renovación total del padrón que se producía cada cinco años, las altas y bajas experimentaban una evolución cíclica con agudos descensos en torno a los años en que se producía tal renovación (figura 2). Las mejoras introducidas en su gestión y su actualización anual han hecho que en la actualidad sea la fuente más utilizada para analizar las migraciones, especialmente las internas ${ }^{15}$

${ }^{15}$ GARCÍA COLL, Arlinda. "Migraciones interiores y transformaciones territoriales"; RÓDENAS, Carmen; MARTÍ, Mónica. "El nuevo mapa de las migraciones interiores en España: Los cambios en el patrón de los sesenta"; RECAÑO VALVERDE, Joaquín. "Los intercambios poblacionales entre las regiones españolas". 
y más específicamente las internas de la población extranjera. ${ }^{16}$ No obstante, estas estadísticas provienen de un registro administrativo como es el padrón de habitantes y, por tanto, sujeto a las posibilidades y limitaciones derivadas de ese carácter de registro administrativo.

Los cambios de residencia no se comunican de forma inmediata a la administración municipal cuando tienen lugar, sino en función de las necesidades de los ciudadanos. Estas dependen en gran medida de las facilidades que el empadronamiento ofrece para el acceso a servicios público y administrativos, por lo que el incremento de estos desde finales de los años setenta, empezando por las elecciones democráticas y continuando con la extensión del Estado de Bienestar, ha introducido acicates para el empadronamiento. Pero también ha supuesto un incentivo para falsos empadronamientos (en domicilios o municipios donde realmente no se reside) por muy diversas razones, sobre todo fiscales o de acceso a esos mismo servicios. Hace 20 años estas estadísticas subestimaban claramente el total de migraciones que se producían, especialmente interiores. Actualmente registran un volumen tal de migraciones que hacen sospechar cierta sobreestimación; pero, sobre todo, no podemos saber en qué momento se pasa de la subestimación a una cifra más fiable, por lo que no permiten utilizarlas para analizar la evolución anual, al menos en el largo plazo. $^{17}$

FIGURA 2

Evolución de las migraciones interiores e internacionales según las Estadísticas de Variaciones Residenciales

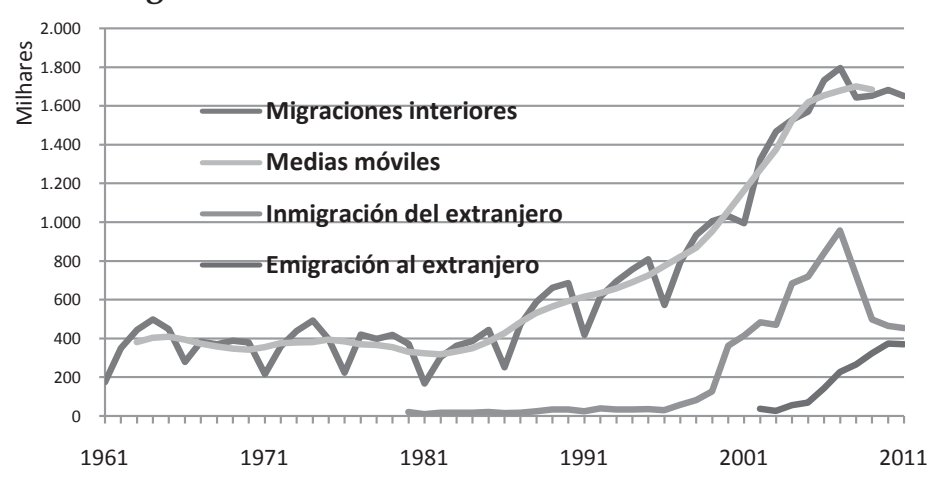

Fuente: elaboración propia a partir de las EVR, INE.

\footnotetext{
${ }^{16}$ PUMARES, Pablo; GARCÍA COLL, Arlinda; ASENSIO, Ángeles. La movilidad laboral y geográfica de la población extranjera en España.

17 SUSINO, op. cit.
} 
No obstante este uso disfuncional del padrón y los cambios en su gestión, las estadísticas de variación residencial son muy valiosas, aunque en su interpretación hay que tener en cuenta al menos los siguientes cambios:

- Como consecuencia de la entrada en vigor de la Ley de Extranjería, entre 1999 y 2000 se produce una ruptura en la serie de las EVR, pues se empadronan muchos más residentes no comunitarios.

- Aunque las EVR empiezan a computar bajas (emigración) a partir de 2002, en 2006 se produce una ruptura, pues se empieza a depurar el padrón de extranjeros presuntamente emigrados que no renuevan su empadronamiento.

- A pesar de las mejoras introducidas en estas estadísticas y de las precauciones que han de tomarse para su interpretación, las EVR no dejan de presentar problemas. De hecho el INE realiza unas Estimaciones de la población actual, como proyección de la población del censo de 2001 que toma como inicial, aplicando el método de componentes, que estima la evolución de los tres fenómenos demográficos básicos, mortalidad, fecundidad y migraciones. De esta forma el propio INE revisa las cifras de inmigración y emigración en el país, con el resultado de una saldo migratorio positivo en el periodo 20072012 de 1.220 .000 personas frente a 1.541.000 de las EVR, consecuencia sobre todo de estimar mayor emigración que las recogidas en las EVR. Así, por ejemplo, en 2011, mientras que las EVR dan un saldo positivo de 84.000 migrantes, las estimaciones de la población actual ofrecen una saldo negativo de 50.0000 habitantes. Estas estimaciones ofrecen cifras quizás más ajustadas, pero no constituyen por sí mismas una nueva fuente.

\section{Las encuestas}

En España hay tres encuestas oficiales sobre migraciones a nivel nacional, dos realizadas en distintos momentos puntuales y una que es anual.

- La encuesta sobre migraciones con mayor continuidad en el sistema estadístico español es la llamada Encuesta de Migraciones (EM), que existe desde 1980 y se realiza junto con la Encuesta de Población Activa (EPA). Desde entonces, ha experimentado varios cambios, algunos de gran calado metodológico. ${ }^{18}$

Estos cambios se han orientado en parte a resolver la evidente subestimación de las migraciones de esta encuesta, sin conseguirlo.

\footnotetext{
${ }^{18}$ MARTí, Mónica; RÓDENAS, Carmen. "Migrantes y migraciones: de nuevo la divergencia en las fuentes estadísticas"; INE. Encuesta de Migraciones. Metodología, 2008; IDEM. Encuesta de Migraciones. Metodología EPA-2002.
} 
Además de las modificaciones de la propia EPA, sobre todo las relativas a reponderaciones y estimaciones a partir de la muestra, la EM ha atravesado cuatro fases distintas. Durante el período 1980-1986, recogía información durante los cuatro trimestres del año, a partir de las viviendas que entraban a formar parte por primera vez en la muestra de la EPA en cada uno de los trimestres, estimándose el número medio de migrantes en el año. Durante el período 1987-1991, se recogía información solo en el segundo trimestre de cada año. Entre 1992 y 1998, se produjeron varias modificaciones en el cuestionario y ampliaciones de la muestra de la EPA. En 1999, junto a una nueva renovación de la EPA, se vuelve a estudiar a los migrantes en los cuatro trimestres del año, pero siguiendo un procedimiento que permite dos estimaciones diferentes: la primera parecida al periodo 1980-1986, la segunda como media anual de las muestras trimestrales completas, de forma que un método permitía corregir parcialmente la subestimación del otro. Con los cambios metodológicos realizados en la EPA a partir de 2005, la EM se obtiene a partir de una submuestra compuesta por los hogares a los que se realiza la encuesta en la sexta y última entrevista. En la figura 3 se recogen como líneas verticales estos cambios.

FIGURA 3

Evolución de los migrantes interiores y provenientes del extranjero según la Encuesta de Migraciones

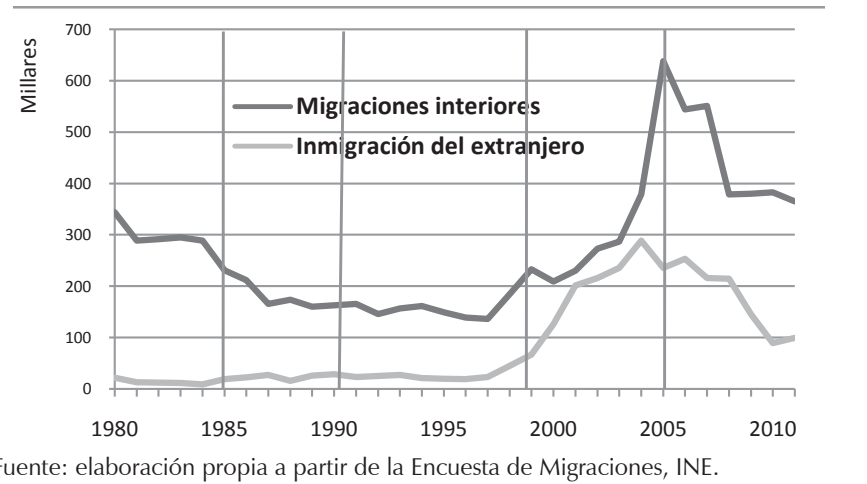

Esta encuesta también mide migrantes, puesto que pregunta sobre el lugar de residencia un año antes. Sin embargo, al ser el periodo de referencia muy corto, son pocos los que migran más de una vez a lo largo del año, por lo que la cifra de migrantes debería acercarse mucho a la de migraciones. Esto es, un efectivo que puede tratarse como un flujo. Sin embargo, el gráfico permite observar la evidente subestimación del fenómeno en comparación con otras 
fuentes. No obstante la línea de la inmigración del extranjero se asemeja en la forma, no en los volúmenes de migrantes, a la recogida en la figura $2 .{ }^{19}$ La línea de migraciones interiores se diferencia no solo en los volúmenes sino también en la forma. Nuestra interpretación es que el problema está en la lista que se utiliza para la selección de la muestra, constituida por los hogares existentes según el padrón. Como los que cambian de vivienda no modifican de forma inmediata su empadronamiento, los hogares más móviles no son recogidos en la muestra.

- La primera de las encuestas que estudia las migraciones, entre otros aspectos, se realizó en 1991. Es la Encuesta Sociodemográfica (ESD), que es muy útil para comparar con las demás fuentes e intentar evaluarlas conjuntamente. Es una encuesta retrospectiva, que investiga todos los acontecimientos demográficos de toda la vida de los encuestados. Permite investigaciones que pongan en relación distintos eventos y situaciones en la vida de los entrevistados. ${ }^{20}$

\section{CUADRO 4}

Migraciones y migrantes en España en el periodo 1981-1991 según distintas fuentes

\begin{tabular}{|c|c|c|c|c|}
\hline & $\begin{array}{l}\text { Estadísticas } \\
\text { de variaciones } \\
\text { residenciales }\end{array}$ & $\begin{array}{l}\text { Censo de } \\
\text { 1991: última } \\
\text { migración }\end{array}$ & $\begin{array}{c}\text { Censo de 1991: } \\
\text { residencia en } \\
1981\end{array}$ & Encuesta \\
\hline Intraprovinciales & 2.274 .973 & 2.478 .050 & 2.086 .030 & 2.478 .363 \\
\hline Interprovinciales & 2.063 .037 & 1.862 .698 & 1.617 .093 & 2.516 .648 \\
\hline Del extranjero & 203.362 & 483.530 & 409.752 & S.D. \\
\hline Total inmigración & 4.541 .372 & 4.824 .278 & 4.112 .875 & 4.995 .011 \\
\hline
\end{tabular}

Fuente: elaboración propia a partir de las fuentes indicadas, INE.

La comparación de las magnitudes absolutas de migraciones y migrantes de las distintas fuentes recogidas en el cuadro 4 debe tener en cuenta que no afecta a los mismos volúmenes de población. En el caso de las EVR, se refiere a toda la población del país en un periodo considerado, en las preguntas retrospectivas de censos y encuestas, a la población superviviente y presente en el momento de la recogida de datos. En la pregunta sobre el lugar de residencia en la fecha del censo anterior, a la población que estuviese presente en ese momento (lo que no incluye a los que entonces aun no habían nacido ni a los que vivían en el extranjero), en la ESD a la población de 10 y más años que es la encuestada, y en la censal sobre la última migración a toda la población. Además, los periodos

\footnotetext{
${ }^{19}$ Para su comparación téngase en cuenta la diferencia en el eje horizontal, que en un caso abarca 50 años y en el otro 30.

${ }^{20}$ RECAÑO VALVERDE, Joaquín; ROIG VILA, Marta. "Internal Migration and Inequalities: The Influence of Migrant Origin on Educational Attainment in Spain".
} 
considerados son ligeramente distintos. No obstante ahorraremos al lector los detalles técnicos y expondremos brevemente los resultados de nuestro análisis.

Las EVR deberían arrojar cifras más altas pues recogen migraciones, mientras que los censos migrantes y la ESD no contabiliza las de los más pequeños; por tanto en los 80 subestimaban el fenómeno. Como cabía esperar, la pregunta censal sobre la última migración arroja cifras superiores a la pregunta sobre la residencia en una fecha anterior, puesto que la primera se dirige a toda la población y la segunda solo a los mayores de diez años. Además, en esta, algunos movimientos pueden no dejar huella cuando se hacen dos migraciones y la última devuelve a sus protagonistas al punto de partida. La ESD es coherente con los datos de los censos de migraciones intraprovinciales, pero llama la atención el mayor volumen de las interprovinciales. Según esto los migrantes de larga distancia tendrían mayor movilidad: harían más migraciones por migrante. ${ }^{21}$

- Tenemos, por último, una encuesta centrada en la situación de los inmigrantes extranjeros, la Encuesta Nacional de Inmigrantes de 2007. Esta encuesta se centra en la investigación del proceso migratorio, desde la decisión de migrar a las estrategias que sustentan todo el proceso, profundizando en la composición y funcionamiento de las redes migratorias, en la movilidad residencial y migratoria dentro del país, y en las dimensiones sociales, laborales y económicas del fenómeno. Esta encuesta define el inmigrante internacional como toda persona nacida en el extranjero y actualmente residente en España, con independencia de su nacionalidad.

En la figura 4 se representa la distribución, según esta encuesta, de los inmigrantes así definidos, de 16 años y más, según su situación legal. Estos resultados podemos compararlos con la diferencia entre extranjeros empadronados y autorizaciones de residencia en vigor. Esta arroja a 1 de enero de 2007 casi 1,5 millones de personas. Aunque esta cifra incluye cerca de un $15 \%$ de menores de 16 años, que no está en la ENI, contrasta fuertemente con los aproximadamente 560.000 inmigrantes en situación irregular de esta encuesta. Posiblemente la explicación esté, en parte, en que los inmigrantes en situación irregular estén subrepresentados, ${ }^{22}$ pero también porque el padrón sobreestima la población extranjera tanto por los falsos empadronamientos que ya comentamos, como por la falta de bajas de los que ya se han ido. ${ }^{23}$ En todo caso, los problemas que plantea el padrón para

\footnotetext{
${ }^{21}$ Desgraciadamente no disponemos de los datos de inmigración del extranjero de la ESD para poder comparar con los censos.

${ }^{22}$ COlECTIVO IOE. "Los inmigrantes en España".

${ }^{23}$ DEVOLDER, Daniel; GIL, Fernando; FORTE, Pere. Estimación del grado de error en el registro de la
} 
seleccionar las unidades a entrevistar que ya hemos señalado respecto a la Encuesta de Migraciones también se pueden dar en esta encuesta. ${ }^{24}$

\section{FIGURA 4}

\section{Distribución según situación legal de residencia de los inmigrantes en la ENI de 2007}

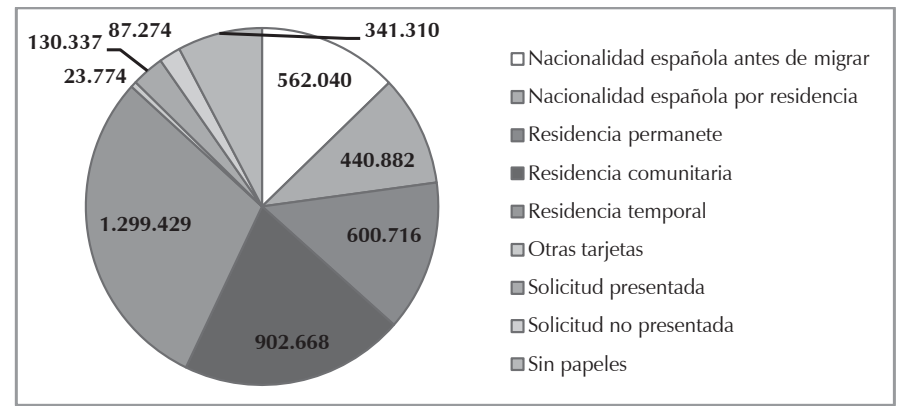

Fuente: elaboración propia a partir de Colectivo IOE. "Los inmigrantes en España".

\section{Otros registros: inmigrantes y extranjeros, migración legal e irregular}

En este epígrafe veremos otros tipos de registros administrativos, con la diferencia respecto al Padrón de habitantes de que estos recogen, en la mayoría de los casos, permisos, autorizaciones o actos administrativos que requieren del cumplimiento de condiciones fijadas normativamente más exigentes que las necesarias para el empadronamiento.

- El más importante es el registro que mide el número de extranjeros con residencia legal en el país, la Estadística de Extranjeros con Certificado de Registro o Tarjeta de Residencia en Vigor, comúnmente denominado autorizaciones de residencia. ${ }^{25}$ La denominación de esta estadística hace referencia a dos regímenes bien diferenciados:

- Régimen comunitario, se aplica a los ciudadanos nacionales de países de la Unión Europea, de otros estados que forman parte del Acuerdo sobre el Espacio Económico Europeo (Islandia, Liechtenstein y Noruega) y de la Confederación Suiza; así como a familiares descendientes o ascendientes de ciudadanos comunitarios. Estos ciudadanos tienen derecho a la libre circulación y residencia, y al ejercicio de una actividad económica en las mismas condiciones que los españoles.

población extranjera en España: un enfoque comparativo.

${ }^{24}$ REHER, David; REQUENA, Miguel. "The National Immigrant Survey of Spain: A new data source for migration studies in Europe".

${ }^{25}$ La estadística es una explotación del Registro Central de Extranjeros, que es un registro administrativo gestionado por la Dirección General de la Policía y de la Guardia Civil, del Ministerio del Interior. 
- Régimen general, que se aplica a los nacionales de terceros países, salvo que les sea de aplicación el Régimen comunitario por ser familiares de ciudadanos comunitarios.

Las estadísticas miden el número de certificados de registro en vigor, que es el documento que han de solicitar los ciudadanos sujetos al régimen comunitario, y de tarjetas de residencia en vigor, para los de régimen general. No constan como residentes los nacionales de terceros países con autorización de estancia para estudios, los que tienen permiso para estancias breves (máxima duración de 3 meses por semestre prorrogable), los trabajadores transfronterizos, los solicitantes de asilo y refugiados, los comunitarios que no hayan solicitado su inscripción en el registro y los de terceros países que tienen caducada su residencia y la están renovando, o no tienen tarjeta de residencia.

Podemos llamarlos "residentes regulares", expresión fácilmente comprensible, frente a los que residen irregularmente en el país, y mucho más apropiada que la de residentes legales frente a ilegales, que también suele utilizarse. Adviértase que los que están regularmente para estancias cortas o por estudios no se consideran verdaderos residentes. Además, pueden estar en situación irregular, tanto los no comunitarios como los comunitarios, por mucho que estos tengan derecho a residir libremente en el país.

Como toda fuente que tenga su origen en registros administrativos, esta ha sufrido fluctuaciones debidas a diversas contingencias derivadas de la gestión del propio registro o de cambios normativos. Los más importantes son los siguientes:

- La estadística existe desde los años 40,26 pero solo a partir de 1991 los ficheros se depuran para contar exclusivamente las autorizaciones y tarjetas de residencia en vigor. La serie anterior no es, por tanto, totalmente comparable.

- La continuidad de las series se ve influida por los procesos de regularización de residentes en situación irregular, de los que se han producido seis: 1985, 1991, 1996, 2000, 2001, 2005. ${ }^{27}$ Todas suponen aumentos en el número de residentes regularizados. Por tanto, en ningún caso se deben interpretar los aumentos interanuales como llegadas de inmigrantes extranjeros, lo que sería tomar como un flujo lo que no es sino variación del efectivo (por ejemplo, en la figura 5 es bien visible el aumento de los residentes de régimen general durante el año 2005).

\footnotetext{
${ }^{26}$ Puede verse en los anuarios estadísticos del INE, disponibles en www.ine.es.

27 AGUILAR, Raquel. "El acceso de los inmigrantes irregulares al mercado de trabajo. Los proceso de regularización extraordinaria y el arraigo laboral y social"; KOSTOVA, Miroslava. "Una evaluación del último proceso de regularización de trabajadores extranjeros en España (febrero-mayo de 2005)".
} 
- La inclusión de los nacionales de nuevos países miembros de la Unión Europea en el régimen comunitario de extranjería, especialmente la incorporación de Bulgaria y Rumanía desde el 1 de enero de 2007, hace que los que estaban en situación irregular puedan acceder de forma inmediata al régimen comunitario (adviértase en la figura 5 el aumento de residentes de régimen comunitario durante el año 2007).

\section{FIGURA 5}

Evolución de los extranjeros residentes según el padrón de habitantes y con certificado de registro o tarjeta de residencia en vigor, según régimen

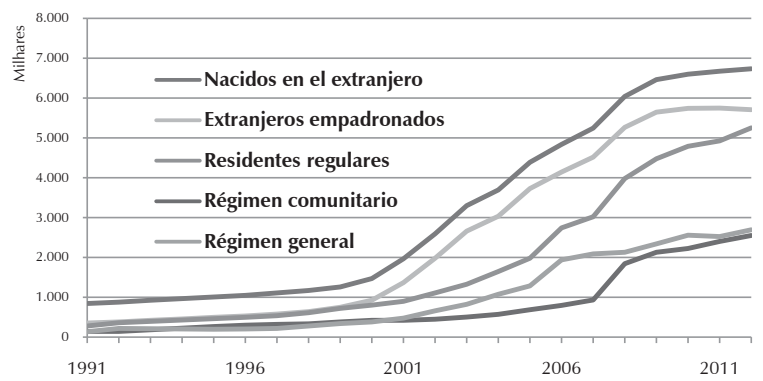

Fuente: elaboración propia a partir del Censo de 1991, Padrón continuo desde 1996 a 2012, INE, y extranjeros con certificado de registro o tarjeta de residencia en vigor, Dirección General de Policía, INE.

La peculiaridad del sistema español, por la que los extranjeros pueden empadronarse aun no teniendo la residencia regularizada permite comparar la evolución de ambas cifras y tener un indicador del volumen aproximado de residentes irregulares. A partir de la aprobación de la Ley de Extranjería el año 2000, el número de empadronados empieza a distanciarse de los residentes legales, llegando a representar un millón y medio más de personas en 2007, para luego reducirse hasta poco menos de medio millón a principios de 2012 (ver figura 5). En todo caso, hay que tener en cuenta en esta comparación el uso fraudulento del empadronamiento ya comentado y que hasta 2006 no empieza a depurarse el padrón de los extranjeros que han abandonado el país.

La estimación de la residencia irregular es siempre difícil. Ya sea que se base en encuestas e informadores clave, ${ }^{28}$ en el análisis de las operaciones de regularización, ${ }^{29} \mathrm{o}$ en esta comparación entre dos fuentes distintas. ${ }^{30}$ En todo caso, podemos concluir que esa cifra de un millón y medio de inmigrantes

\footnotetext{
${ }^{28}$ COlETIVO IOE, op. cit.

${ }^{29}$ IZQUIERDO, Antonio. La inmigración en España 1980-1990.

${ }^{30}$ IZQUIERDO, Antonio; LEÓN-ALFONSO, Sandra. "La inmigración hacia dentro: argumentos sobre la necesidad de la coordinación de las políticas de inmigración en un Estado multinivel".
} 
irregulares está sobreestimada. Su rápida disminución posterior no responde solamente a la depuración del padrón, sino al cambio de coyuntura económica que ha hecho que seguramente abandonen el país más inmigrantes irregulares que los que tienen residencia legal. Esta comparación entre extranjeros e inmigrantes nacidos en otro país, nos obliga a insistir que extranjero no es lo mismo que inmigrante. ${ }^{31} \mathrm{Al}$ hablar de efectivos de migrantes existentes en un país en un momento determinado hay que precisar: son inmigrantes también los nacionales que vuelven de una emigración anterior o los nacionales que han nacido en el extranjero; son extranjeros pero no inmigrantes los que han nacido de padres extranjeros dentro del país; son inmigrantes pero no extranjeros los naturalizados o nacionalizados. El concepto de migrante se refiere siempre a la situación actual en relación a algún momento anterior, mientras que el de extranjero se refiere a un estado o condición actual de la persona. Los dos son efectivos, pero no es lo mismo ser inmigrante que extranjero.

Los medios de comunicación y, con demasiada frecuencia también los medios académicos, tienden a considerar inmigrantes únicamente los provenientes de países menos desarrollados y que vienen a España por motivos económicos. Sin embargo, hay que subrayar que un migrante es una persona que cambia de lugar de residencia, cualquiera sea su origen o destino y los motivos por los que lo haga. Entre la inmigración extranjera, por tanto, están incluidos los provenientes de los países más desarrollados, especialmente de la UE. ${ }^{32}$ La Encuesta Nacional de Inmigrantes se acerca a este concepto al nacido en el extranjero, con independencia de su nacionalidad, que incluye a los inmigrantes que al nacionalizarse han dejado de ser extranjeros, pero excluye a los antiguos emigrantes españoles que al retornar se convierten en inmigrantes.

Para el estudio de la inmigración proveniente del extranjero, no tanto de la evolución de sus efectivos, como de las características de los inmigrantes, debemos acudir a otras fuentes complementarias, todas provenientes de registros administrativos, que reseñamos brevemente:

- La estadística Concesiones de nacionalidad española por residencia es una explotación de la base de datos gestionada por la Dirección General de los Registros y del Notariado del Ministerio de Justicia que registra todos los trámites relativos a la solicitud, concesión y denegación de la nacionalidad española por residencia. Sin embargo, la difusión de la

\footnotetext{
${ }^{31}$ GARRIDO, Luis. "Para cuantificar a los extranjeros".

${ }^{32}$ En el lenguaje popular a estas personas no se les llama casi nunca inmigrantes, utilizándose otros apelativos, como "guiris", algo parecido a lo que ocurre en Latinoamérica con la expresión "gringos". Algunos académicos e instituciones denominan "inmigrantes económicos" a los provenientes de los países menos desarrollados (Observatorio Permanente de la Inmigración. Indicadores de la Población y el Asilo en España).
} 
estadística la realiza el Ministerio de Empleo y Seguridad Social a través de su página web. ${ }^{33}$ Efectivamente, muchos inmigrantes extranjeros han dejado de ser extranjeros por adquisición de la nacionalidad española, pero no por eso han dejado de ser inmigrantes. Para analizar la inmigración internacional sería mejor estudiar la evolución de los nacidos en el extranjero, más que los extranjeros. Pues bien, desde 1991 a 2011 se han producido más de 770.000 nacionalizaciones. Si sumamos esta cifra al número de extranjeros empadronados obtenemos unos 6,5 millones de inmigrantes de origen extranjero en 2012, aunque no totalmente cierta pues parte de los nacionalizados habrá muerto o abandonado el país.

- La estadística Visados expedidos en Oficinas Consulares es una explotación de la base de datos creada y mantenida por el Ministerio de Asuntos Exteriores y de Cooperación que registra todos los trámites relativos a la solicitud, expedición y denegación de visados. Desde 1996 se diferencian cuatro tipos de visados: de tránsito aeroportuario, de tránsito territorial, de estancia para periodos que no excedan de tres meses, prorrogables, y de residencia que presenta especificidades dependiendo de su finalidad. Los tres primeros tipos de visados están sujetos a la legislación comunitaria, pero no el de residencia. No se exige visado a los nacionales de países de la UE ni a muchos de países Latinoamericanos. Parte de los inmigrantes residentes en situación irregular entran con visados distintos de residencia o sin necesidad de visado, por lo que su entrada es legal, pero no así su residencia. Además, para regularizar la residencia con frecuencia es necesario tramitar un visado en el país de origen. El resultado es que la concesión de visados no es un buen instrumento para analizar los flujos de entrada en el país.

- La estadística Trabajadores Extranjeros Afiliados a la Seguridad Social en alta laboral procede de la explotación del fichero de afiliación de los trabajadores a los distintos regímenes de la Seguridad Social, cuya gestión corresponde a la Tesorería General de la Seguridad Social y al Instituto Social de la Marina. Recoge la información de los trabajadores extranjeros que cotizan al sistema de la Seguridad Social, pero un mismo trabajador puede aparecer tantas veces como situaciones de cotización tenga, por ejemplo si tiene varias actividades laborales, por lo que las altas laborales no se corresponden con el número de trabajadores. Obviamente esta estadística solo recoge a

${ }^{33}$ Cf. http://extranjeros.mtin.es/es/InformacionEstadistica/. 
trabajadores ocupados y cotizantes, no a ocupados en actividades informales o sumergidas, ni a parados ni a extranjeros inactivos.

- La estadística de Autorizaciones de trabajo a extranjeros procede del Ministerio de Administraciones Públicas que recoge las autorizaciones de trabajo y residencia y las autorizaciones para trabajar resueltas por las Áreas o Dependencias Provinciales de Trabajo e Inmigración de las Delegaciones y Subdelegaciones de Gobierno, o por las Oficinas de Extranjeros, según los casos, y completados con datos de la Dirección General de Inmigración. Es ofrecida por el Ministerio de Empleo y Seguridad Social en http://www.empleo.gob.es/.

- La estadística de Población extranjera solicitante de asilo proviene de la Subdirección General de Asilo (Oficina de Asilo y Refugio), de la Dirección General de Política Interior perteneciente al Ministerio del Interior. Es importante señalar que los solicitantes de asilo están protegidos y no están incluidos en la estadística de extranjeros residentes.

- Otras estadísticas relevantes para estudiar la inmigración internacional son: Extranjeros con autorización de estancia por estudios en vigor, Contratos registrados correspondientes a trabajadores extranjeros, Demandantes de empleo extranjeros, Alumnado extranjero matriculado en enseñanzas no universitarias, Alumnado extranjero matriculado y graduado en enseñanzas universitarias, Homologación, convalidación y reconocimiento en España de títulos y estudios extranjeros, Nacidos en España de madre o padre extranjero, Matrimonios celebrados en España con al menos un cónyuge extranjero, Defunciones de extranjeros en España.

Todos estos registros no miden específicamente migraciones ni migrantes, pero pueden ser utilizados para su estudio. Como ejemplo, citemos a Izquierdo y Martínez ${ }^{34}$.

\section{La emigración española}

Ya se ha señalado que desde 2002 las EVR recogen la emigración tanto de españoles como de extranjeros. Pero antes ha habido dos fuentes tradicionales para medir los flujos de emigrantes:

- Una es la emigración asistida por el Instituto Español de Emigración, desde su creación en 1956 hasta su desaparición en 1985, aunque todavía seguirá existiendo después de esa fecha. Al principio se

${ }^{34}$ IZQUIERDO, Antonio; MARTÍNEZ, Raquel. "La inmigración en España en 2001". 
identifica con la emigración continental a Europa, y más tarde se generaliza. Esta emigración abarca tanto la permanente, para estancias de más de una año, como las temporales y de temporada, por lo que es necesario contar solo las primeras si se quiere estudiar las verdaderas migraciones, que como se dijo al principio son cambios de lugar de residencia.

- La otra es la antigua estadística de fronteras que en la práctica se refiere a los embarques, ya sea por vía marítima o, más tarde, aérea, y que es la forma en que en España se ha controlado tradicionalmente la emigración transoceánica, que como se denomina en los anuarios estadísticos. También se ha utilizado para contabilizar los retornos. Hasta que un cambio legislativo en 1971 acaba con la práctica de asimilar a los emigrantes o retornados con los embarques o desembarques de pasajeros de tercera clase en buques que tocan puertos españoles que duraba desde 1882 .

Otras fuentes para conocer el número de españoles residentes en el extranjero, así como los flujos de la emigración, son las de los países de acogida, especialmente los censos. No son, por tanto, fuentes españolas pero se hacen constar aquí por la importancia que en el estudio de la emigración española han tenido. ${ }^{35}$ Pero a este respecto, hay que advertir que las diferencias en los sistemas estadísticos de los países de entrada y salida arrojan cifras a veces muy distintas. Depende de la cobertura de las estadísticas, pero también de las definiciones que se apliquen para que un extranjero sea considerado inmigrante. ${ }^{36}$

\section{FIGURA 6}

\section{Evolución de la emigración española asistida continental y transoceánica}

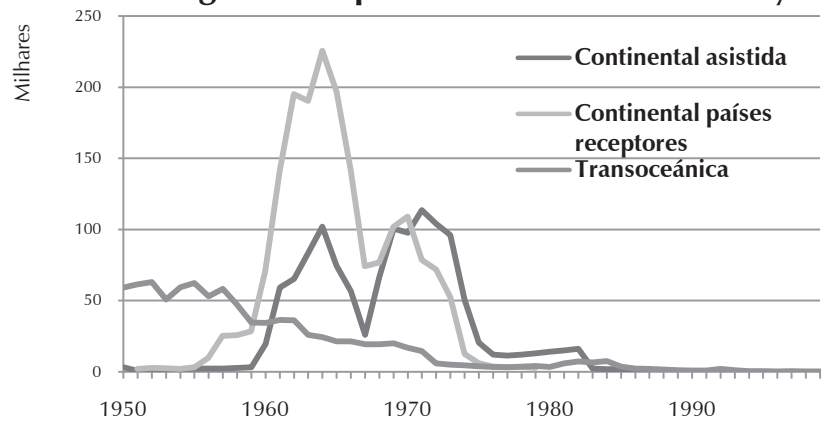

Fuente: elaboración propia a partir de las series de emigración asistida y transoceánica publicadas en los Anuarios Estadísticos, INE; la inmigración a los países receptores tomadas de Nadal, 1984, que la toma de la tesis doctoral de Angels Pascual.

\footnotetext{
${ }^{35}$ RUBIO, Javier. La emigración española a Francia; VILAR, Juan B.; VILAR, María José. La emigración española a Europa en el siglo XX; NADAL, Jordi. La población española (siglos XVI a XX).

${ }^{36}$ POULAIN, op. cit. p. 88.
} 
La tradicional emigración española a América, muy intensa entre mediados del siglo XIX y principios del XX, está bien documentada. ${ }^{37}$ En la figura 5 vemos que tras un repunte después de la guerra civil, la emigración a América desciende y es sustituida por la emigración continental, hacia otros países de Europa. A mediados de los años 70 esta corriente también se interrumpe abruptamente y España, poco a poco, primero por el retorno de los antiguos emigrantes, luego por la llegada de extranjeros, se convertirá en país de inmigración. Las estadísticas de los países receptores muestran un volumen aun mayor. ${ }^{38}$

Por otra parte, debemos contar también las fuentes que miden efectivos de españoles en el extranjero:

- En el Padrón de Españoles Residentes en el Extranjero (PERE) se inscriben las personas de nacionalidad española (sea o no esta su única nacionalidad) que residen habitualmente fuera de España, a partir del registro de matrícula de las oficinas y secciones consulares. Su explotación estadística es reciente y refleja un crecimiento intenso de los españoles en el extranjero. Sin embargo, este aumento es engañoso, porque los que más ha crecido con los españoles nacidos en el país de residencia, mientras que apenas crecen los españoles nacidos en España y que viven en el extranjero, que en 2012 solo representaban un 36\%. Esta estadística nos puede hacer confundir, de nuevo, la nacionalidad y la migración. Buena parte de los españoles que viven en el extranjero no son, en realidad, emigrantes, pues no solo han nacido fuera, sino que nunca han vivido en España.

- El Censo electoral de españoles residentes en el extranjero (CERA) tiene el mismo origen consular, pero solo recoge los españoles mayores de edad con derecho a voto. Si se hace constar aquí es porque su explotación estadística es mucho más antigua. Pero hay que tener en cuenta que, en los últimos cuatro años, el PERE recoge cerca de un 20\% más de personas que él CERA, los menores de edad.

\section{Conclusiones}

Como se ha visto, existen múltiples fuentes para el estudio de las migraciones. En parte es así porque no hay estadísticas de migraciones como

\footnotetext{
${ }^{37}$ CARRERAS, Albert; TAFUNELL, Xavier (coords.). Estadísticas históricas de España. Siglos XIX y XX.

${ }^{38}$ A partir de 1968 los datos de Suiza son incompletos, siendo este el tercer país receptor de inmigración española, lo que explica que en la figura 6 la línea no se sitúe por encima de la emigración asistida.
} 
las de otros fenómenos demográficos, claras e incontestables; como las de nacimientos y defunciones que provienen del registro civil, por ejemplo. Esto puede generar dudas y sospechas respecto a cada una de las fuentes.

Ninguna de las reseñadas aquí goza de absoluta y total fiabilidad y validez. De ellas no se puede asegurar la total constancia, regularidad y seguridad de las medidas, ni su exacto ajuste a la realidad, su veracidad. Pero siendo esto importante, aun lo es más que de ninguna de ellas se puede afirmar que carezcan totalmente de estas cualidades. En última instancia, tan importante como las propias fuentes es el uso que los investigadores hagamos de ellas, para lo que necesitamos conocerlas en profundidad. Hay que saber cómo funciona el aparato de medida, las operaciones estadísticas y administrativas que lo sustentan. Por eso, a pesar de las discrepancias entre las fuentes y sus inconsistencias, tenemos una imagen bastante precisa de los procesos migratorios que han afectado a España durante la segunda mitad del siglo XX y el principio del siglo XXI. Y tenemos los instrumentos para poder seguir profundizando en su conocimiento.

\section{Bibliografía}

AGUILAR, Raquel. "El acceso de los inmigrantes irregulares al mercado de trabajo. Los proceso de regularización extraordinaria y el arraigo laboral y social", in Revista del Ministerio de Trabajo y Asuntos Sociales, v. 63, 2006, p. 175-195.

CARRERAS, Albert; TAFUNELL, Xavier (coords.). Estadísticas históricas de España. Siglos XIX y XX. Bilbao: Fundación BBVA, 2003.

COHEN, Arón. "Reflexiones a propósito de una lectura estadística de la inmigración. La inmigración entre imágenes y cifras", in CHECA, Francisco; CHECA, Juan Carlos; ARJONA, Ángeles (eds.). Inmigración y derechos humanos. La integración como participación social. Barcelona: Icaria, 2004.

COLECTIVO IOE. "Los inmigrantes en España”, in Documentación Social, v. 66, 1987. ; FERNÁNDEZ, Mercedes. Encuesta Nacional de Inmigrantes 2007: el mercado de trabajo y las redes sociales de los inmigrantes. Madrid: Ministerio de Trabajo e Inmigración, 2010.

COURGEAU, Daniel. Méthodes de mesure de la mobilité spatiale: migrations internes, mobilité temporaire, navettes. París: INED, 1988.

CRUZ VILLALÓN, Josefina; FERIA, José María, FERNÁNDEZ SALINAS, Víctor; PEDREGAL, Belén (dir.). Los movimientos migratorios con origen y destino en Andalucía. 1981-1991. Sevilla: Instituto de Estadística de Andalucía, 1996.

DEVOLDER, Daniel; GIL, Fernando; FORTE, Pere. Estimación del grado de error en el registro de la población extranjera en España: un enfoque comparativo. Centre d'Estudis Demogràfics, 2006. 
FERIA, José María et alii. Migraciones y movilidad residencial en Andalucía. 19912001. Sevilla: Instituto de Estadística de Andalucía, 2008.

FERIA, José María; SUSINO, Joaquín. "La dimensión regional y los nuevos referentes de las migraciones interiores en España", in FERNÁNDEZ CORDÓN, Juan Antônio; LEAL MALDONADO, Jesús (coords.). Análisis territorial de la demografía española. Madrid: Fundación Fernando Abril Martorell, 2006.

GARCÍA COLL, Arlinda. "Migraciones interiores y transformaciones territoriales", in PONS, Juan José et alii (eds). Territorio y movilidad interior de la población en España. Pamplona: EUNSA, 2009, p. 13-40.

GARCÍA COLL, Arlinda; STILLWELL, John. Internal migration and regional population dynamics in Europe: Spain case study. Working Paper, 2000/8. Universidad de Leeds, 2000.

GARRIDO, Luis. "Para cuantificar a los extranjeros", in Economistas, v. 99, 2004, p. 28-37.

INE (Instituto Nacional de Estadística). Anuarios estadísticos. Madrid: Instituto Nacional de Estadística, varios años.

. Censo de la Población de España. 1970. Tomo III: Características de la Población. Madrid: Instituto Nacional de Estadística, 1974.

. Censo de Población. 1981. Tomo I, volumen 1: Características de la Población. Resultados Nacionales. Madrid: INE, 1985.

. Censo de Población. 1991. Resultados Nacionales. Madrid: INE, 1993.

. Censos de Población y Vivienda. 2001. Resultados definitivos. Madrid: 2004.

. Migraciones. Quinquenio 1961-1965. Madrid: INE, 1991.

. Migraciones. Quinquenio 1966-1970. Madrid: INE, 1991.

. Migraciones. Quinquenio 1976-1980. Madrid: INE, 1992.

. Migraciones. Quinquenio 1981-1985. Madrid: INE, 1993.

. Encuesta de Migraciones. Metodología EPA-2002. Madrid: INE, 2002.

. Encuesta de Migraciones. Metodología. Madrid: INE, 2008.

. Encuesta de Población Activa. EPA. Encuesta de migraciones. 1980 a 1997.

Madrid: INE, varios años.

. Encuesta Sociodemográfica 1991. Tomo II: Resultados Nacionales. Volumen

2: Movimientos Migratorios y Vivienda. Madrid: INE, 1993.

IZQUIERDO, Antonio (dir.). Demografía de los extranjeros. Incidencia en el crecimiento de la población. Bilbao: Fundación BBVA, 2006.

. La inmigración en España 1980-1990. Madrid: Ministerio de Trabajo y Seguridad Social, 1992.

IZQUIERDO, Antonio; LEÓN-ALFONSO, Sandra. "La inmigración hacia dentro: argumentos sobre la necesidad de la coordinación de las políticas de inmigración en un Estado multinivel", in Política y Sociedad, v. 45, n. 1, 2008, p. 11-39.

IZQUIERDO, Antonio; MARTÍNEZ, Raquel. "La inmigración en España en 2001", in IZQUIERDO, Antonio (dir.). Inmigración: mercado de trabajo y protección social en 
España. Madrid: Consejo Económico y Social, 2003, p. 99-181.

KOSTOVA, Miroslava. "Una evaluación del último proceso de regularización de trabajadores extranjeros en España (febrero-mayo de 2005). Un año después". Documento de Trabajo (DT) 15/2006. Real Instituto Elcano, 2006.

LÓPEZ de Lera, Diego; DOMÍNGUEZ, Iciar. Inmigración Extranjera en Andalucía 1991-2001. Sevilla: Instituto de Estadística de Andalucía, 2002.

MARTÍ, Mónica; RÓDENAS, Carmen. "Migrantes y migraciones: de nuevo la divergencia en las fuentes estadísticas", in Estadística Española, v. 46, n. 156, 2004, p. 293-321.

NADAL, Jordi. La población española (siglos XVI a XX). Barcelona: Ariel, 1984.

OBSERVATORIO Permanente de la Inmigración, OPI. Indicadores de la Población y el Asilo en España, 1, mayo. Ministerio de Trabajo y Asuntos Sociales, 1998.

POULAIN, Michel. "La mesure de la migration internationale", in AIDELF (Association Internationale des Démographes de Langue Française). Les migrations internationales: problèmes de mesure, évolutions récentes et efficacité des politiques: Séminaire de Calabre, 810 septembre 1986. París: Instituto National d'Etudes Demographiques, 1988, p. 5-11.

PUMARES, Pablo; GARCÍA COLL, Arlinda; ASENSIO, Ángeles. La movilidad laboral y geográfica de la población extranjera en España. Madrid: Ministerio de Trabajo y Asuntos Sociales, 2006.

RECAÑO VALVERDE, Joaquín. "Los intercambios poblacionales entre las regiones españolas", in FERNÁNDEZ CORDÓN, Juan A.; LEAL MALDONADO, Jesús (coords.). Análisis territorial de la demografía española. Madrid: Fundación Fernando Abril Martorell, 2006.

RECAÑO VALVERDE, Joaquín; ROIG VILA, Marta. "Internal Migration and Inequalities: The Influence of Migrant Origin on Educational Attainment in Spain", in European Sociological Review, v. 19, n. 3, 2003, p. 299-317.

REHER, David; REQUENA, Miguel. "The National Immigrant Survey of Spain: A new data source for migration studies in Europe", in Demographic Research, v. 20, n. 12, 2009, p. 253-278.

RÓDENAS, Carmen; MARTÍ, Mónica. “El nuevo mapa de las migraciones interiores en España: Los cambios en el patrón de los sesenta", in Investigaciones Regionales, v. 6, 2005, p. 21-39.

RUBIO, Javier. La emigración española a Francia. Barcelona: Ariel, 1974.

SILVESTRE RODRÍGUEZ, Javier. "Viajes de corta distancia: una visión espacial de las migraciones interiores en España 1877-1930", in Revista de Historia Económica, v. 19, n. 2, 2001, p. 247-283.

SUSINO, Joaquín. "La evolución de las migraciones interiores en España: una evaluación de las fuentes demográficas disponibles", in Papers, v. 96, n. 3, 2011, p. 853-881.

UIAA. Diccionario demográfico multilingüe. Bélgica, 1985.

VILAR, Juan B.; VILAR, María José. La emigración española a Europa en el siglo XX. Madrid: Arco, 1999. 


\section{Abstract}

Demographic sources for the study of migration in Spain

This paper presents the available sources in Spain to analyze the evolution of migration, focusing on quantifying the contingent of migrants and migration flows. Both internal and international migration are considered, since many sources are available to study them. The article distinguishes purely statistical sources from those based on administrative records, as well as those that study the whole universe from the ones based on surveys, stressing the need to rigorously distinguish contingents from flows.

Keywords: Statistical sources; Internal migration; International migration; Migrants; Foreigners.

Recibido para publicación en 25/08/2012.

Aceptado para publicación en 02/10/2012.

Received for publication in August, 25 th 2012. Accepted for publication in October, 02 ${ }^{\text {th }}, 2012$. 